\title{
A new polymorphic methanogen, closely related to Methanocorpusculum parvum, living in stable symbiosis within the anaerobic ciliate Trimyema sp.
}

\author{
B. J. Finlay, ${ }^{1 *}$ T. M. EmbleY ${ }^{2}$ and T. FenCHEL ${ }^{3}$
}

${ }^{1}$ Institute of Freshwater Ecology, Windermere Laboratory, The Ferry House, Ambleside, Cumbria LA22 0LP, UK

${ }^{2}$ Microbiology Group, Department of Zoology, Natural History Museum, Cromwell Road, London SW7 SBD, UK

${ }^{3}$ Marinbiologisk Laboratorium (University of Copenhagen), Strandpromenaden 5, DK-3000 Helsingør, Denmark

(Received 13 July 1992; revised 23 September 1992; accepted 7 October 1992)

\begin{abstract}
A new anaerobic microbial consortium has been discovered: the partners are the ciliated protozoon Trimyema sp. and a single species of methanogen. The consortium has been maintained in culture for more than four years. Each ciliate contains up to $\mathbf{3 0 0}$ symbiotic bacteria; many are relatively small and irregularly disc-shaped, and these are distributed throughout the host's cytoplasm, whereas those which are attached to the ciliate's hydrogenosomes are significantly larger and profusely dentate. This attachment is interpreted as an adaptation to maximize capture by the bacteria of the $\mathrm{H}_{2}$ escaping from hydrogenosomes. The 16S rRNA gene of the symbionts has been partially sequenced, and fluorescent oligonucleotide probes have been constructed and used to detect the different morphotypes of the symbiont within the ciliate. The symbionts belong to a new species of archaeobacterium which is a close relative of the free-living methanogen Methanocorpusculum parvum.
\end{abstract}

\section{Introduction}

Ciliates belonging to the genus Trimyema are all anaerobic: they were first recorded from sewage tanks (Lackey, 1925), and they are frequently encountered in anoxic freshwater habitats (e.g. Wagener et al., 1990b). Some marine species are also known; $T$. echinometrae is an endocommensal of sea urchins (Grolière et al., 1980).

Trimyema compressum is frequently present in anoxic freshwater sediments. The ciliate was long known to harbour bacteria-sized particles in its cytoplasm (see Augustin et al., 1987) although the identity of these remained obscure until Wagener \& Pfennig (1987) demonstrated that at least some of them were methanogenic bacteria. The same authors discovered that endosymbiotic methanogens were always present when the ciliates were freshly enriched from the natural environment. The methanogens were rod-shaped, variable in length $(1.6-3.3 \mu \mathrm{m})$ and relatively wide $(0.65 \mu \mathrm{m})$. Wagener \& Pfennig (1987) obtained a monoxenic culture of the ciliate, but during continued cultivation, the endosymbiotic methanogens were lost. This loss of

*Author for correspondence. Tel. (05394) 42468; fax (05394) 46914.

The nucleotide sequence determined in this work has been submitted to EMBL and has been assigned the accession number Z16412. symbionts occurred without apparent effect upon the growth of the host ciliates.

Wagener et al. $(1990 a)$ then re-infected these aposymbiotic ciliates with two strains of methanogens isolated from other anaerobic ciliates. The introduced bacteria remained viable for at least two months but the symbiosis was again unstable, and the methanogens were lost within one week following stimulation of the host growth rate. Holler \& Pfennig (1991) had a similar experience: their re-infected association was lost after two months. Interestingly, however, these authors dispelled any suggestion that the methanogens were only passive residents by showing that methane replaced formate as a major metabolic end-product when 'symbiotic' methanogens were introduced.

Little else is known in detail concerning the anaerobic metabolism of Trimyema. It is clear, however, that in some strains at least, hydrogenase is present in the microbodies (Zwart et al., 1988; Goosen et al., 1990 b; Broers et al., 1991) and that the latter are, therefore, likely to be $\mathrm{H}_{2}$-evolving redox organelles ('hydrogenosomes'; see Müller, 1988; Finlay, 1990): the anaerobic equivalent of mitochondria (Finlay \& Fenchel, 1989). The production of $\mathrm{H}_{2}$ within Trimyema would explain the attractiveness of this habitat for methanogens: indeed, an interspecies $\mathrm{H}_{2}$ transfer is believed to be the basis of methanogen endosymbiosis in a variety of other 
anaerobic ciliate species (Fenchel \& Finlay, 1991 $a$; Finlay \& Fenchel, 1992b).

It is a finding common to all previous studies of Trimyema endosymbiosis that rod-shaped methanogens (and, sometimes, other anaerobic bacteria: Goosen et al., 1990b; Detcheva et al., 1981) are found living inside ciliates when they are collected from the natural environment. None of the Trimyema symbionts have been identified and it is apparent that none enjoy a stable endosymbiosis when the ciliate is brought into culture: bacterial growth is apparently readily uncoupled from that of the host, leading to loss of symbionts from the ciliate. Here, we present the discovery of a new type of symbiosis within a species of Trimyema-an endosymbiosis that is stable, having been maintained in the laboratory for four years (approximately 1000 ciliate generations), involving a methanogen which is not rodshaped but disc-shaped and polymorphic. This symbiont has been identified by determining the base sequence of its $16 \mathrm{~S}$ rRNA, and its identity has been verified by in situ hybridization with fluorescent oligonucleotide probes.

\section{Methods}

Collection and cultivation of ciliates. Anoxic sediment was collected with a Jenkin corer from the deepest part $(3.7 \mathrm{~m})$ of a small productive pond (Priest Pot, Cumbria; see Finlay et al., 1988). The sediment was transferred under a stream of $\mathrm{N}_{2}$ to serum vials half-filled with buffered (pH 7) SES medium outgassed with $\mathrm{N}_{2}$ (Fenchel \& Finlay, 1990), with dried cereal leaves (Sigma) as carbon source. The growth of the natural anaerobic bacterial flora stimulated population growth of the ciliate Trimyema, which was subsequently isolated using micropipettes from all other eukaryotes, and maintained in SES medium, under a headspace of $\mathrm{N}_{2}$, with the same mixed microbial flora as food. The ciliates have been maintained in culture for four years.

Microscopy. For as long as these cultures have been maintained, the ciliates have contained symbiotic bacteria which show the characteristic autofluorescence of methanogens (Doddema \& Vogels, 1978). This was detected and photographed after preparing ciliates as described by Finlay \& Fenchel (1989) (with fixation in $4 \%, v / v$, formaldehyde solution). Hydrogenase activity in the ciliate was detected cytochemically (Zwart et al., 1988) using nitroblue tetrazolium as electron acceptor, $\mathrm{H}_{2}$ as substrate and $\mathrm{N}_{2}$ as control. The characteristics of the ciliate's infraciliature were determined after silver staining (FernándezGaliano, 1976) and the ciliate was identified by reference to Augustin et al: (1987). Ciliates were prepared for transmission electron microscopy as described by Finlay \& Fenchel (1991b).

Isolation of ciliate consortia. Ciliates carrying endosymbiotic methanogens were isolated from mixed microbial cultures using nylon sieves in a range of mesh sizes $(5-100 \mu \mathrm{m})$. Ciliates were finally collected and washed several times on $5 \mu \mathrm{m}$ sieves, then re-suspended in anoxic, membrane-filtered spent culture medium and concentrated by gentle centrifugation $(1000 \mathrm{~g} ; 1 \mathrm{~min})$. The ciliates remained intact in the final preparation, and microscopic examination of a sample of the latter confirmed the absence of methanogen autofluorescence from the few free-living prokaryote contaminants remaining.

PCR amplification of symbiont $16 S$ ribosomal DNA. Approximately $10^{4}$ ciliates were centrifuged at $4000 \mathrm{~g}$ for $5 \mathrm{~min}$ then washed once with distilled water before resuspension in $200 \mu \mathrm{l}$ of $5 \%(\mathrm{w} / \mathrm{v})$ Chelex 100
(Walsh et al., 1991) prepared in sterile Millipure water. The suspension was heated at $56^{\circ} \mathrm{C}$ for $15 \mathrm{~min}$, vortexed, then boiled for $5 \mathrm{~min}$. The primers and PCR protocol for amplifying approximately $1-1.1 \mathrm{~kb}$ of archaeobacterial small subunit ribosomal DNA are described by Embley et al. (1992a). Each amplification contained $20 \mu \mathrm{l}$ of the supernatant from the Chelex extraction. The amplified material was sequenced using published primers and procedures (Embley, 1991; Embley et al., 1992a).

Design of probes. The sequence obtained for the endosymbiont was compared to the published rRNA data base for Archaeobacteria (Neefs et al., 1991). An oligonucleotide probe was constructed (SYM5: 5' CTGCATCGACAGGCACT) to bind specifically to rRNA from the symbiont. The probe recognized a target sequence within helix 17 , by reference to the Halobacterium cutirubrum secondary structure (Olsen et al., 1991; Neefs et al., 1991). A control probe designed to bind selectively to all archaeobacterial rRNA (Stahl \& Amman, 1991) was also prepared. The probes were synthesized using Amino-link 2 (Applied Biosystems) and coupled to tetramethyl-6-carboxyrhodamine or 6-carboxyfluorescein (Applied Biosystems) using the manufacturer's protocols. Hybridization experiments were carried out at $48^{\circ} \mathrm{C}$ for 4-6 h using procedures described by Stahl \& Amman (1991) with minor modifications (Embley et al., 1992a). After hybridization, each slide was mounted using Citifluor antifadent (AF1, Citifluor Ltd, London, $\mathrm{UK}$ ) and examined with an Olympus BH2 epifluorescence microscope and specific filter combinations designed to maximize visualization of fluorescein and rhodamine fluorescence.

\section{Results}

\section{Identity of the ciliate}

The ciliate was easily identified as a representative of the genus Trimyema (vestibulum and cytostome near anterior end; restriction of somatic ciliature to oblique spirals; prominent caudal cilium; small size [in vivo, most cells are $30-50 \mu \mathrm{m}$ in length]). Moreover, the tapering of the posterior end, together with the distinguishing presence of only three somatic ciliary spirals (Figs 1-3) indicates that the organism could be Trimyema compressum Lackey (1925). However, we are unhappy with this identification. In some crucial details, the silver-
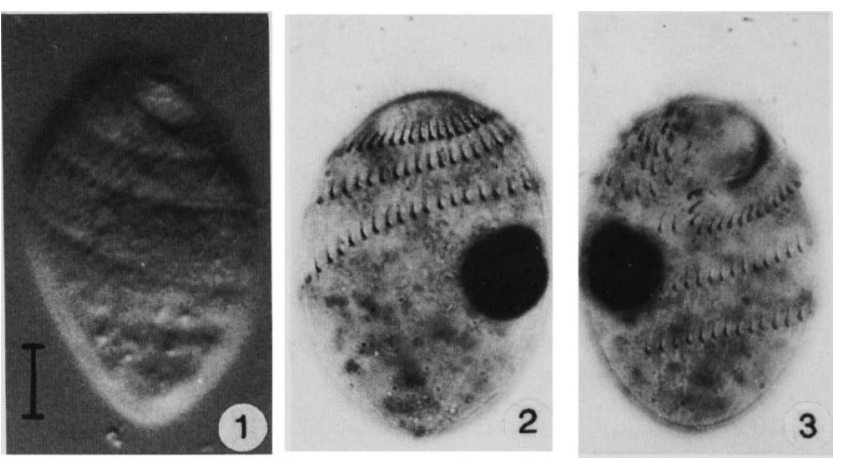

Figs 1-3. Whole cells of Trimyema sp. Fig. 1. Living cell, Nomarski illumination - the three anterior ciliary spirals are obvious. Figs 2 and 3. Silver carbonate impregnated specimens, showing the dorsal (Fig. 2) and ventral (Fig. 3) surface and the stained kinetosomes of the somatic kineties. The dark spherical body is the macronucleus. Bar, $10 \mu \mathrm{m}$. 
stained infraciliature is clearly different from that described for T. compressum. Augustin et al. (1987) and Serrano et al. (1988) both state that this species has 50-60 longitudinal somatic kineties, and the scanning electron micrographs provided by Wagener \& Pfennig (1987) (the 'Konstanz' strain of $T$. compressum) show more than 50 longitudinal somatic kineties, as does the 'Nijmegen' strain (a gift from Dr C. K. Stumm), which we have also examined after impregnation with silver carbonate. In contrast, the ciliates of our strain have only $37-40$ longitudinal kineties. We also find that the structure of the brosse and the numbers of kinetosomes in some kineties of our ciliate differ significantly from those described for $T$. compressum by Serrano et al. (1988) (G. Esteban and others, unpublished results). It is likely therefore that the ciliate we have in culture is not identical to the organism previously described as $T$. compressum. Accordingly it is identified here simply as Trimyema sp.

\section{Ultrastructure of the symbiotic bacteria}

Any thin section through the cytoplasm of this ciliate reveals electron-dense bodies, of various shapes, enclosed singly in vacuoles (arrows in Fig. 4). These bodies are quite distinct from food bacteria, which are usually less electron-dense and almost always occur in groups, each group being enclosed by a food vacuole membrane. Some of the electron-dense bodies are considerably larger than others and have an indented outline. At high magnification (Fig. 5) it is apparent that each dentate body is enclosed by a cell wall and that each body is surrounded by hydrogenosomes. The identification of the latter is unambiguous - they are bounded by two membranes, the inner membrane occasionally shows infolding into cristae (this is not obvious in Fig. 5) and the hydrogenosomes can just be resolved using light microscopy following cytochemical staining for hydrogenase. In some ciliates the stained hydrogenosomes were seen by light microscopy to completely surround the large dentate bodies.

In some respects, Trimyema sp. appears to be a typical freshwater anaerobic ciliate: it contains hydrogenosomes rather than mitochondria as the energy-yielding redox organelles, and it contains intracellular bodies which are prokaryotes, which show the characteristic autofluorescence of methanogens (Fig. 6) and which are, therefore, probably symbiotic methanogens dependent on $\mathrm{H}_{2}$ gas produced by the hydrogenosomes. On the question of the identity of the methanogens, there are two clear possibilities: either they are polymorphs of the same species, or more than one species of methanogen is present. The identity of the methanogens was resolved by sequencing PCR-amplified 16S rRNA gene fragments, and the use of fluorescent oligonucleotide probes, as follows.

\section{$r R N A$ sequences}

The products of the PCR reactions designed to amplify symbiont ribosomal DNA were examined using agarose gel electrophoresis, and a single weak band of about $1-1.1 \mathrm{~kb}$ was detected. No bands were observed in reactions lacking template. The amplified material was precipitated, and sufficient product was available to directly sequence 854 bases stretching from position 23 to the distal base of helix 33 on the Halobacterium cutirubrum secondary structure (Neefs et al., 1991). The sequence has been deposited in the EMBL database. The sequence was unambiguous and there was no evidence of 'double sequence' in highly variable regions (e.g. helix 17). This suggests that it came from a single species. Analysis of the sequence revealed that it originated from an archaeobacterium; the archaeobacterial signature bases (Winker \& Woese, 1991) at positions $338(\mathrm{G}), 367$ (C) and 393 (G) were all present and the bases between positions 405 and 499 could be folded in the secondary structure typical of archaeobacteria. The sequence of the symbiont was compared to published sequences for archaeobacteria (Neefs et al., 1991; Olsen et al., 1991). Pairwise comparisons of sequence revealed that the symbiont sequence closely resembled (13 differences; 796 bases compared) that for Methanocorpusculum parvum.

In order to prove that the new sequence originated from the Trimyema endosymbiont, a specific fluorescent oligonucleotide probe was designed and used in wholecell hybridizations. Some of the results are shown in Figs $7-10$, which are shown alongside a picture of polymorphic autofluorescing methanogens in one ciliate (Fig. 6). Figs 7 and 8 show, respectively, the reaction within one ciliate to simultaneous probing with an archaeobacterial rRNA specific probe and the specific symbiont probe. It is clear that the same particles, of various shapes and sizes, fluoresce in response to each probe. The abundance, and the shapes and sizes, of particles in each ciliate which respond to the specific probe (Figs 9 and 10) clearly resemble the autofluorescing particles shown in Fig. 6. Thus it appears that the autofluorescence is indeed due to the methanogen $\mathrm{F}_{420}$ coenzyme, that these methanogens belong to a single species and that they are polymorphic inside each ciliate.

Representative stages in this polymorphic methanogen transformation are shown in Figs 11 to 21. The smallest forms are disc-shaped and slightly less than $1 \mu \mathrm{m}$ in length. These are never attached to hydrogenosomes. They give rise to a continuous series of bacterial shapes by a transformation which involves a significant increase in size (although possibly not of mass) and progressive 

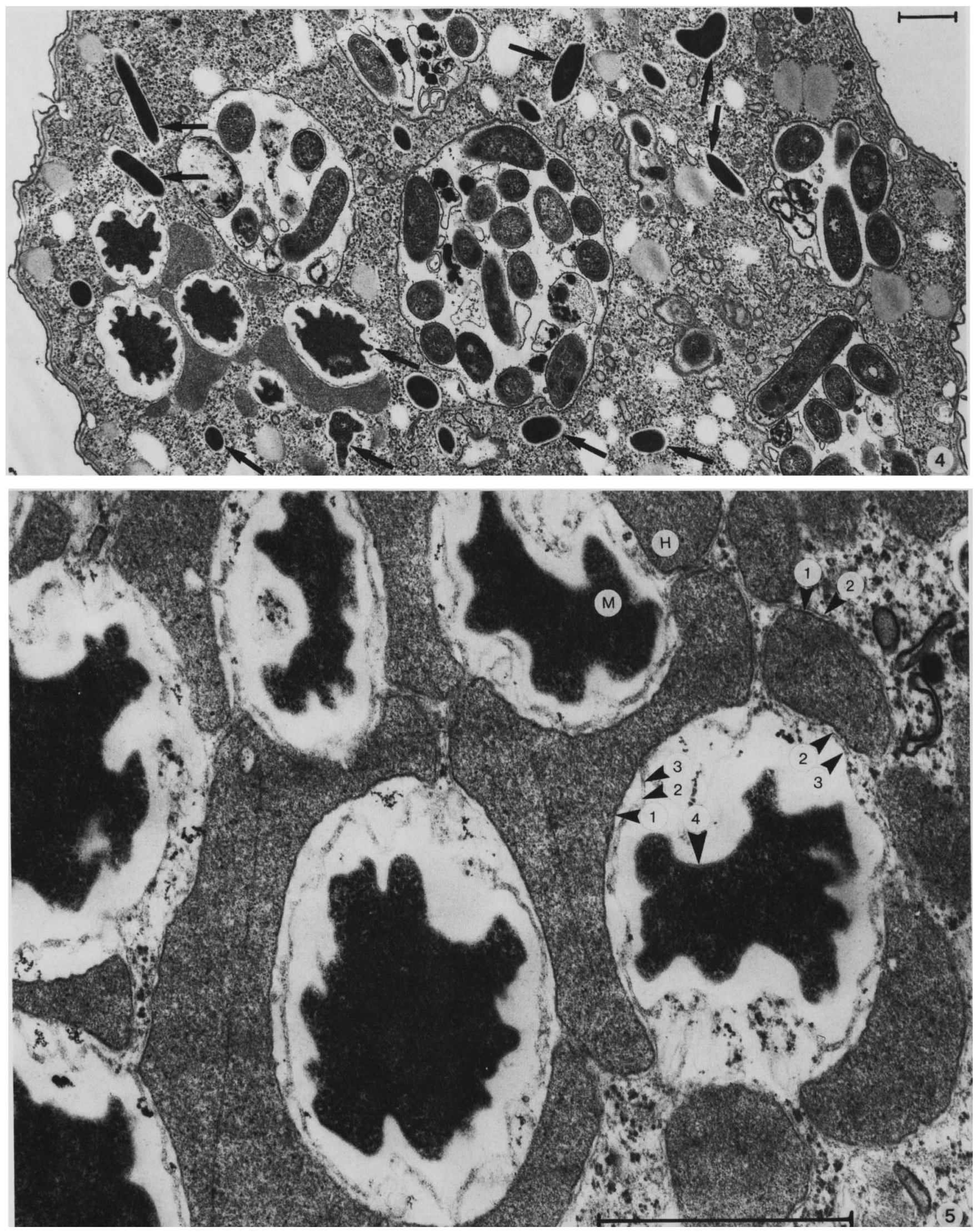

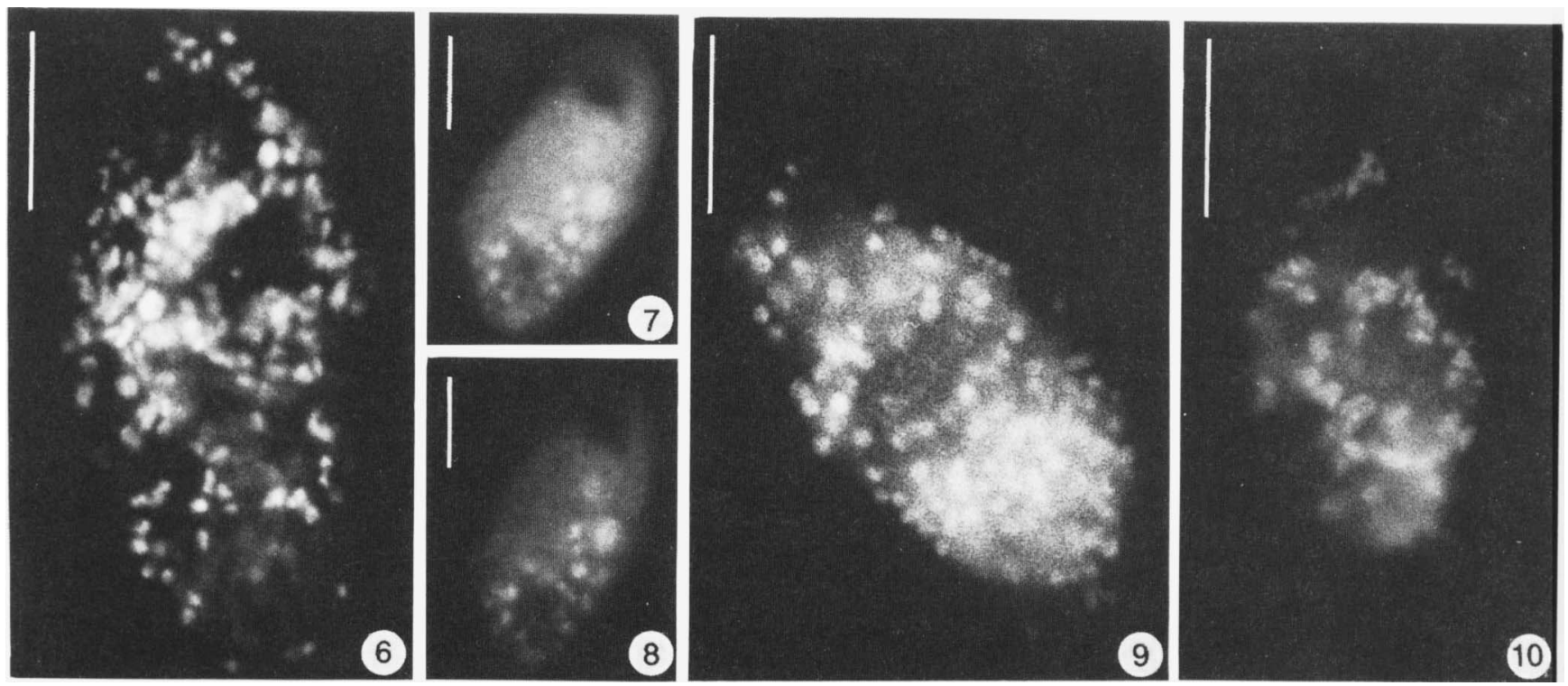

Fig. 6. Autofluorescing methanogens within one ciliate. The various shapes and sizes of methanogens are obvious. Individual ciliates contain up to 300 autofluorescing methanogens. Bar, $10 \mu \mathrm{m}$.

Figs 7 and 8. Fluorescence images resulting from simultaneous probing of the same ciliate with an archaeobacterial probe (Fig. 7) and a probe specific to the symbiotic methanogen (Fig. 8). Bar, $10 \mu \mathrm{m}$.

Fig. 9. Symbiotic methanogens of various shapes and sizes, fluorescing in response to the specific symbiont probe. Bar, $10 \mu \mathrm{m}$.

Fig. 10. Symbiotic methanogens, some grouped in clusters (cf. Figs 4 and 5), fluorescing in response to the specific symbiont probe. Bar, $10 \mu \mathrm{m}$.

invagination of the cell wall. In the final stages of this transformation, the methanogens appear stellate and almost totally enclosed by hydrogenosomes. Note that roughly spherical fluorescing particles of approximately the same size are obvious in Fig. 6 (methanogen autofluorescence) and Fig. 9 (specific probe). The latter stages in the morphological transformation always have closely attached hydrogenosomes. This attachment is apparently produced by fusion between the outer hydrogenosomal membrane and the ciliate membrane which encloses the methanogen. The same process has been described for other ciliate species (Finlay \& Fenchel, 1989, 1991a).

\section{Discussion}

It appears that two quite different types of endosymbiosis can become established between methanogens and the ciliate Trimyema. The first type involves rod-shaped methanogens which can be easily lost. The reasons for this are unknown; it may be because the methanogens are inhibited, or because methanogen growth becomes uncoupled from that of the host. Alternatively it may simply be something to do with the conditions of laboratory cultivation: we have, for example, discovered that some species of anaerobic ciliates lose their methanogens when cultures are held for a prolonged period at temperatures higher than about $27^{\circ} \mathrm{C}$, whereas the ciliates retain their symbionts when held at $10^{\circ} \mathrm{C}$.

The second type of association, as described in this paper, is quite different: the methanogens involved are not rod-shaped, the association is stable, and the symbiont volume fraction remains relatively constant (symbionts account for approximately $1 \%$ of total consortium biovolume, irrespective of ciliate size; B. J. Finlay \& T. Fenchel, unpublished results) as in other ciliate species which also have stable methanogen endosymbioses (Finlay \& Fenchel, 1992a, b). It is likely

Figs 4 and 5. Endosymbiotic bacteria in Trimyema sp. Fig. 4. Electron-dense methanogens with various shapes are enclosed individually in vacuoles within the ciliate cytoplasm (arrows). Several large vacuoles, each containing many (non-methanogen) food bacteria are also shown. The stellate forms towards the left are shown at higher magnification in Fig. 5. Bar, $1 \mu \mathrm{m}$. Fig. 5. The electron-dense stellate structures are irregularly-shaped methanogens (M; with arrow (4) to cell wall) surrounded by hydrogenosomes $(\mathrm{H})$. The latter may become associated with several bacteria - contact being maintained by apparent fusion of the outer hydrogenosomal membrane and the ciliate membrane which encloses the methanogen $(1,2$, inner and outer hydrogenosomal membrane respectively; 3 , ciliate membrane surrounding vacuole which encloses methanogen; 4 , cell wall of methanogen). Bar, $1 \mu \mathrm{m}$. 


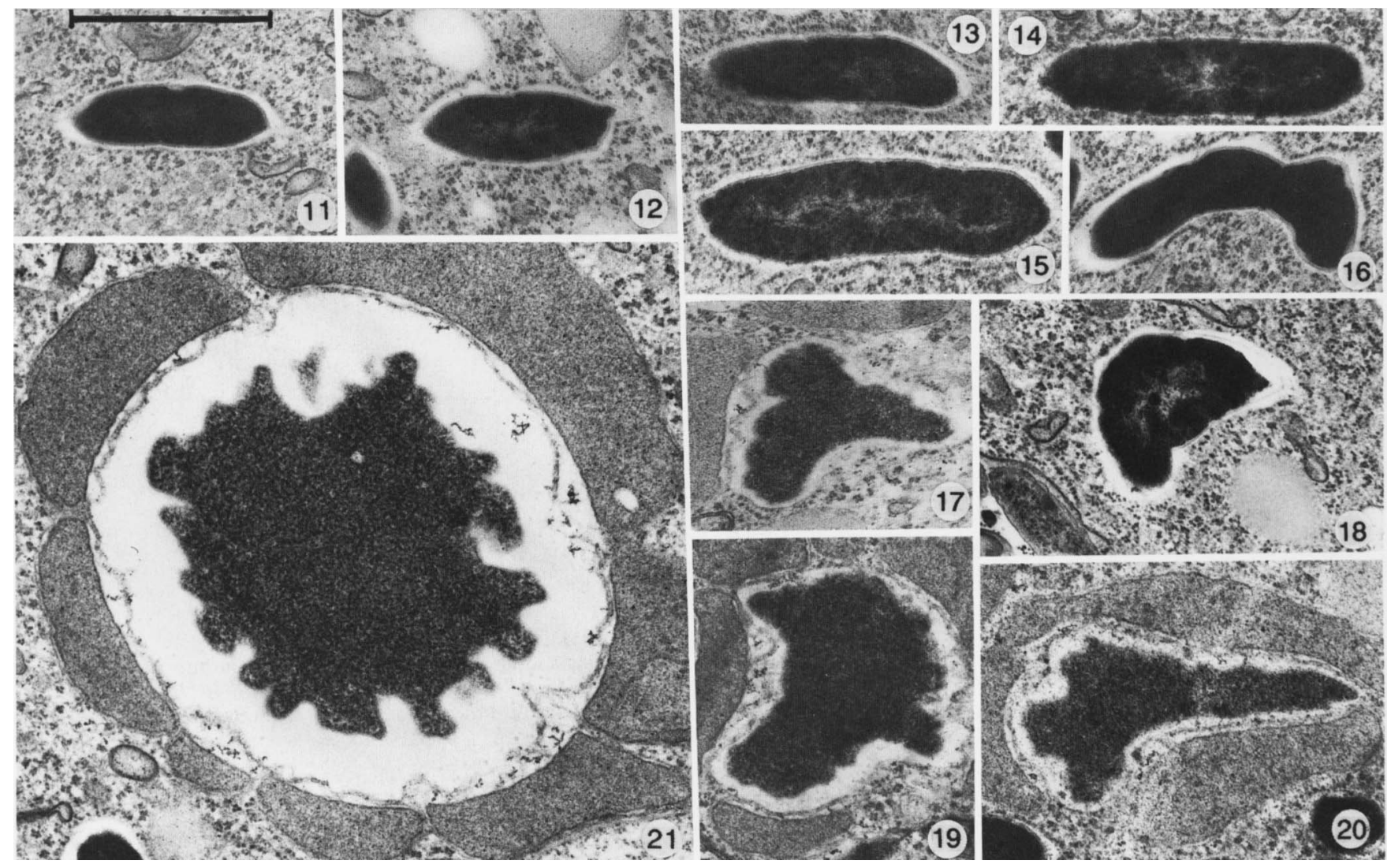

Figs 11-21. Polymorphic transformation of endosymbiotic bacteria in Trimyema sp. Fig. 11. Disc-shaped methanogen before transformation (bar, $1 \mu \mathrm{m}$ ). Figs 12-21. Size and shape variants of the disc-shaped methanogen, arranged in a plausible chronological sequence and terminating in the stellate form, completely surrounded by hydrogenosomes (Fig. 21). The later stages of transformation (Figs 17, 19, 20) are accompanied by an increasingly intimate association with hydrogenosomes.

that the two types of association are mutually exclusive and that they occur in different ciliate species. The ciliate we have studied (Trimyema sp.) supports endosymbiotic methanogens of the second type, whereas Trimyema compressum, which is clearly a different ciliate species, contains rod-shaped endosymbionts which are easily lost from the ciliate.

Trimyema is not the only ciliate genus known to embrace different species, each having different types of endosymbiotic methanogens. Within the genus Metopus, for example, $M$. palaeformis contains rod-shaped methanogen endosymbionts whereas in $M$. contortus the symbionts are disc-shaped and polymorphic. Similarly, in Plagiopyla nasuta, the methanogens are rod-shaped (Goosen et al., 1988) whereas in P. frontata their shape is plastic, and they are arranged in stacks of alternating methanogens and hydrogenosomes (Fenchel \& Finlay, $1991 c$ ).

Since we have demonstrated a hydrogenase in this cultured strain of Trimyema, it is likely that an interspecies $\mathrm{H}_{2}$ transfer underpins the symbiotic association. The constant symbiont volume fraction is consistent with the idea that the methanogens are completely dependent on this $\mathrm{H}_{2}$ for growth and that the growth rates of the two symbiotic partners are approximately equal. Thus it is unremarkable that this methanogen persists within the ciliate and it is improbable that the methanogen's link with its host will be severed by 'statistical outgrowth'.

Electron microscopy also reveals abundant evidence in support of interaction between ciliate and methanogens. This is particularly clear in the thin sections, which show hydrogenosomes forming a complete shell around each methanogen (e.g. Fig. 21), the latter having been 'transformed' by extensive indentation of the cell wall (the length of the circumference traced by the enclosing ciliate membrane is in all cases almost identical to that of the cell wall of the encapsulated methanogen). It is unlikely that we are simply witnessing fixation artefacts since all other bacteria and cell contents are wellpreserved. Cell wall indentation significantly increases the surface area to volume ratio of the methanogen and the whole process may be viewed as a mechanism by which the methanogen increases the efficiency of uptake of $\mathrm{H}_{2}$, and possibly other substrates, diffusing from the surrounding hydrogenosomes. We have argued else- 
where (Fenchel \& Finlay, 1991 $b, 1992)$ that this transfer of $\mathrm{H}_{2}$ in particular could be of benefit to both ciliate and methanogens. The ciliate would benefit because the $\mathrm{H}_{2}$ pressure would be maintained low enough to permit an energy-efficient hydrogen-evolving metabolism in the hydrogenosomes; and the methanogens would benefit because of the guaranteed supply of substrate $\left(\mathrm{H}_{2}\right)$.

The 16S rRNA sequence we have determined for the symbiotic methanogen in Trimyema sp. shares little similarity with the sequence previously determined for the rod-shaped, non-transforming symbiotic Methanobacterium sp. which lives in the anaerobic ciliate Metopus palaeformis (Embley et al., 1992a). However, the polymorphic character of the symbiont of Trimyema sp. might indicate some similarity with the symbiont in Metopus contortus, in which polymorphic transformation has also been documented (Finlay \& Fenchel, 1991 a). Van Bruggen et al. (1986) isolated a symbiont from $M$. contortus; the symbiont was cultured, and it was given the new species name Methanoplanus endosymbiosus. The sequence we have obtained from the Trimyema sp. symbiont is very different from those that have been determined for Methanoplanus species. Using our own isolate of the $M$. contortus - methanogen consortium, we recently found that the symbiont sequence is very similar to published sequences for the free-living methanogen Methanocorpusculum parvum (Embley et al., 1992b). Moreover, the sequence from the symbiont of Trimyema sp. is also similar to Methanocorpusculum parvum, but different ( 10 differences; 840 bases compared) from that obtained from the $M$. contortus symbiont. Thus it appears that in the two reported cases where polymorphic methanogens have been documented from anaerobic ciliates, the methanogens are similar to each other, and interestingly, they are related to a free-living species which is also known to be polymorphic in response to changes in culture conditions and physiological state (Zellner et al., 1987, 1989). Work in progress will seek to establish the precise position of the Trimyema sp. symbiont within the phylogeny of the methanogens.

We acknowledge financial assistance from the Natural Environment Research Council (UK) and the Danish Natural Science Research Council. Ken Clarke, Dr Genoveva Esteban, and Ruth Hindle provided invaluable assistance with electron microscopy, silver staining, and cultivation, respectively.

\section{References}

Augustin, H., Foissner, W. \& Adam, H. (1987). Revision of the genera Acineria, Trimyema and Trochiliopsis (Protozoa, Ciliophora). Bulletin of the British Museum (Natural History) 52, 197-224.

Broers, C. A. M., Stumm, C. K. \& Vogels, G. D. (1991). Axenic cultivation of the anaerobic free-living ciliate Trimyema compressum. Journal of Protozoology 38, 507-511.

Detcheva, R., De Puytorac, P. \& Grolière, C. A. (1981). Some ultrastructural characteristics of the polysaprobic ciliate Trimyema compressum. Transactions of the American Microscopical Society 100 , 65-73.

DodDema, H. J. \& Vogels, G. D. (1978). Improved identification of methanogenic bacteria by fluorescence microscopy. Applied and Environmental Microbiology 36, 752-754.

Embley, T. M. (1991). The linear PCR reaction: a simple and robust method for sequencing amplified rRNA genes. Letters in Applied Microbiology 13, 171-174.

Embley, T. M., Finlay, B. J., Thomas, R. H. \& Dyal, P. L. (1992a). The use of rRNA sequences and fluorescent probes to investigate the phylogenetic positions of the anaerobic ciliate Metopus palaeformis and its archaeobacterial endosymbiont. Journal of General Microbiology 138, 1479-1487.

Embley, T. M., Finlay, B. J. \& BRown, S. (1992b). RNA sequence analysis shows that the symbionts in the ciliate Metopus contortus are polymorphs of a single methanogen species. FEMS Microbiology Letters 97, 57-62.

FenCHEL, T. \& FinLAY, B. J. (1990). Anaerobic free-living protozoa: growth efficiencies and the structure of anaerobic communities. FEMS Microbiology Ecology 74, 269-276

Fenchel, T. \& Finlay, B. J. (1991 a). The biology of free living anaerobic ciliates. European Journal of Protistology 26, 201-215.

FenCHEL, T. \& FinlaY, B. J. (1991 $b$ ). Endosymbiotic methanogenic bacteria in anaerobic ciliates: significance for the growth efficiency of the host. Journal of Protozoology 38, 18-22.

FENCHEL, T. \& FinLAY, B. J. (1991c). Synchronous division of an endosymbiotic methanogenic bacterium in the anaerobic ciliate Plagiopyla frontata Kahl. Journal of Protozoology 38, 22-28.

Fenchel, T. \& Finlay, B. J. (1992). Production of methane and hydrogen by anaerobic ciliates containing symbiotic methanogens. Archives of Microbiology 157, 475-482.

FERNANDEZ-Galiano, D. (1976). Silver impregnation of ciliate protozoa: procedure yielding good results with the pyridinated silver carbonate method. Transactions of the American Microscopical Society 95, 557-560.

Finlay, B. J. (1990). Physiological ecology of free living protozoa. Advances in Microbial Ecology 11, 1-35.

Finlay, B. J. \& FenChel, T. (1989). Hydrogenosomes in some anaerobic protozoa resemble mitochondria. FEMS Microbiology Letters 65, 311-314.

Finlay, B. J. \& FenChel, T. (1991 $a$ ). Polymorphic bacterial symbionts in the anaerobic ciliated protozoon Metopus. FEMS Microbiology Letters 79, 187-190.

Finlay, B. J. \& Fenchel, T. (1991 $b$ ). An anaerobic protozoon, with symbiotic methanogens, living in municipal landfill material. FEMS Microbiology Ecology 85, 169-180.

Finlay, B. J. \& FENCHEL, T. (1992a). An anaerobic ciliate as a natural chemostat for the growth of endosymbiotic methanogens. European Journal of Protistology 28, 127-137.

FinLAY, B. J., \& FeNCHEL, T. (1992b). Methanogens and other bacteria as symbionts of free-living anaerobic ciliates. Symbiosis 14, 375-390.

Finlay, B. J., Berninger, U.-G., Clarke, K. J., Cowling, A. J., Hindle, R. M. \& Rogerson, A. (1988). On the abundance and distribution of protozoa and their food in a productive freshwater pond. European Journal of Protistology 23, 205-217.

Goosen, N. K., Horemans, A. M. C., Hillebrand, S. J. W., Stumm, C. K. \& Vogels, G. D. (1988). Cultivation of the sapropelic ciliate Plagiopyla nasuta Stein and isolation of the endosymbiont Methanobacterium formicicum. Archives of Microbiology 150, 165-170.

Goosen, N. K., Drift, C. van der, Stumm, C. K. \& Vogels, G. D. $(1990 a)$. End products of metabolism in the anaerobic ciliate Trimyema compressum. FEMS Microbiology Letters 69, 171-176.

Goosen, N. K., W AGeNeR, S. \& STUMm, C. K. (1990 b). A comparison of two strains of the anaerobic ciliate Trimyema compressum. Archives of Microbiology 153, 187-192.

Grolière, C.-A., PuytoraC, P. DE \& Grain, J. (1980). Observations de quelques espèces de ciliés endocommensaux d'échinides du Golfe du Mexique et de la Mer des Antilles. Protistologica 16, 233-239.

Holler, S. \& PFenNig, N. (1991). Fermentation products of the anaerobic ciliate Trimyema compressum in monoxenic cultures. Archives of Microbiology 156, 327-334.

LACKEY, J. B. (1925). Studies on the biology of sewage disposal. The 
fauna of Imhoff tanks. New Jersey Agricultural Experiment Station Bulletin no. 417, 1-39.

MüLLER, M. (1988). Energy metabolism in protozoa without mitochondria. Annual Review of Microbiology 42, 465-488.

NeEFs, J.-M., VAN de Peer, Y., De Rijk, P., Goris, A. \& De Wachter, R. (1991). Compilation of small ribosomal subunit RNA sequences. Nucleic Acids Research 19, Supplement, 1987-2015.

Olsen, G. J., LaRson, N. \& WoEsE, C. R. (1991). The ribosomal RNA data base project. Nucleic Acids Research 19, Supplement, 20172021.

Serrano, S., Martin-Gonzalez, A. \& Fernandez-Galiano, D. (1988). Trimyema compressum Lackey, 1925: morphology, morphogenesis and systematic implications. Journal of Protozoology 35, 315-320.

Stahl, D. A. \& Amman, R. I. (1991). Development and application of nucleic acid probes in bacterial systematics. In Nucleic Acid Techniques in Bacterial Systematics, pp. 205-248. Edited by E. Stackebrandt \& M. Goodfellow. Chichester: John Wiley.

Van Bruggen, J. J. A., Zwart, K. B., Hermans, J. G. F., Van Hove, E. M., Stumm, C. K. \& Vogels, G. D. (1986). Isolation and characterisation of Methanoplanus endosymbiosus sp. nov., an endosymbiont of the marine sapropelic ciliate Metopus contortus Quennerstedt. Archives of Microbiology 144, 367-374.

WAGENER, S. \& PFENNIG, N. (1987). Monoxenic culture of the anaerobic ciliate Trimyema compressum Lackey. Archives of Microbiology 149, 4-11.

Wagener, S., Bardele, C. F. \& Prennig, N. (1990a). Functional integration of Methanobacterium formicicum into the anaerobic ciliate Trimyema compressum. Archives of Microbiology 153, 496501.

Wagener, S., Schulz, S. \& Hanselmann, K. (1990 $b$ ). Abundance and distribution of anaerobic protozoa and their contribution to methane production in Lake Cadagno (Switzerland). FEMS Microbiology Ecology 74, 39-48.

Walsh, P. S., MetzGer, D. A. \& Higuchi, R. (1991). Chelex 100 as a medium for simple extraction of DNA for PCR-based typing from forensic material. Biotechniques 10, 506-513.

WINKER, S. \& WoEse, C. R. (1991). A definition of the domains Archaea, Bacteria and Eucarya in terms of small subunit ribosomal RNA characteristics. Systematic and Applied Microbiology 14, 305-310.

Zellner, G., Alten, C., Stackebrandt, E., Conway de Macario, E. \& WINTER, J. (1987). Isolation and characterization of Methanocorpusculum parvum, gen. nov., spec. nov., a new tungsten requiring, coccoid methanogen. Archives of Microbiology 147, 13-20.

Zellner, G., Stackebrandt, E., Messner, P., Tindall, B. J., Conway DE Macario, E., KNeIFel, H. \& Sleytr, U. B. (1989). Methanocorpusculaceae fam. nov., represented by Methanocorpusculum parvum, Methanocorpusculum sinense spec. nov. and Methanocorpusculum bavaricum spec. nov. Archives of Microbiology 151, 381-390.

Zwart, K. B., Goosen, N. K., van SchiJndel, M. W., Broers, C. A. M., Stumm, C. K. \& Vogels, G. D. (1988). Cytochemical localization of hydrogenase activity in the anaerobic protozoa Trichomonas vaginalis, Plagiopyla nasuta and Trimyema compressum. Journal of General Microbiology 134, 2165-2170. 